\title{
Inventário virtual artístico: um projeto educativo de resgate da memória histórico-cultural da cidade de Jaguariaíva/PR ${ }^{1}$
}

\author{
Inventario virtual artístico: un proyecto educativo de rescate de la \\ memoria histórico-cultural de la ciudad de Jaguariaíva / PR
}

\author{
Artistic virtual inventory: an educational project to rescue the historical- \\ cultural memory of the city of Jaguariaiva / PR
}

\author{
Cely Kaori Hirata ${ }^{2}$ \\ Pedro Francisco Cataneli ${ }^{3}$
}

\begin{abstract}
Resumo
O presente artigo tem por finalidade divulgar as ações desenvolvidas pelo grupo de pesquisa: "Inventário das artes plásticas da cidade de Jaguariaíva" do Instituto Federal do Paraná, Campus Jaguariaíva. Com o intuito de contribuir para com o processo educativo de conscientização da arte, cultura e história da cidade de Jaguariaíva, a equipe propõe a criação de um inventário artístico em formato de hipertexto, ou seja, uma plataforma digital contendo informações de obras artísticas que fazem referência à cultura local e que pode ser acessada pela rede mundial de computadores, potencializando a comunicação e conferindo a autonomia no caminho que o internauta deseja percorrer pelo sítio eletrônico. O inventário virtual vincula-se ao projeto de pesquisa que busca refletir e analisar os cruzamentos entre identidade e memória, matéria e forma, criador e sua obra. Objetivou-se com este trabalho a ação educativa popular para a valorização, preservação e divulgação de artistas populares locais que expressam em suas criações plásticas as representações do contexto histórico e cultural da cidade.
\end{abstract}

Palavras-Chave: Bens Culturais; Inventário; Hipertexto; Processo Criativo; Identidade cultural.

\section{Resumen}

El presente artículo tiene por finalidad divulgar las acciones desarrolladas por el grupo de investigación "Inventário das artes plásticas da cidade de Jaguariaíva", del Instituto Federal de Paraná, Campus Jaguariaíva. Con el propósito de aportar en el proceso educativo de concientización acerca del arte, cultura e historia de Jaguariaíva, el equipo propone la creación de un inventario artístico en formato de hipertexto, es decir, una plataforma digital conteniendo informaciones sobre obras artísticas que hacen referencia a la cultura local y que pueden ser accedidas por Internet, de manera a alargar la comunicación y ofrecer autonomía cuanto al camino que desea recorrer el internauta en el sitio eletrónico. El inventario virtual se vincula al proyecto de investigación como herramienta para reflexionar y analizar los cruces entre identidad y memoria, materia y forma, creador y su obra. Se planteó con ese trabajo la acción educativa popular para la valoración y divulgación de artistas populares locales que imprimieron en sus obras plásticas las representaciones del contexto histórico y cultural de la ciudad.

\footnotetext{
1 Artigo apresentado no Simpósio Temático: Repensar, Refletir, Interpretar e Reinterpretar a Memória, identidade e o patrimônio cultural da América Colonial, durante o II Seminário Latino-Americano de Estudos em Cultura - SEMLACult em Foz do Iguaçu/PR, Brasil, 2018.
}

2 Mestranda em Educação: Teoria e Prática de Ensino; Instituto Federal do Paraná - IFPR; Jaguariaíva, Paraná, Brasil; cely.hirata@ifpr.edu.br.

\footnotetext{
${ }^{3}$ Mestre em História Social; Instituto Federal do Paraná - IFPR; Jaguariaíva, Paraná, Brasil; pedro.cataneli@ifpr.edu.br.
} 
Palabras clave: Bienes culturales; inventario; hipertexto; Proceso Creativo; Identidad cultural.

\begin{abstract}
The purpose of this article is to divulge the actions developed by the research group "Inventory of plastic arts of the city of Jaguariaíva", established at the Instituto Federal do Paraná, Campus Jaguariaíva. In order to contribute to the educational process of awareness of the art, culture and history of the city of Jaguariaíva, the team proposes the creation of an artistic inventory in hypertext format, that is, a digital platform containing information of artistic works that make reference to the local culture and that can be accessed by the world-wide computer network, boosting the communication and granting the autonomy in the way that the internet user wants to go through the electronic site. The virtual inventory is linked to the research project that seeks to analyze and reflect on the intersections among identity and memory, matter and form, creator and his work. The objective of this work is the popular educational action for the appreciation, preservation and dissemination of local popular artists who express in their artistic creations the representations of the historical and cultural context of the city.
\end{abstract}

Keywords: Cultural goods; Inventory; Hypertext; Creative process; Cultural identity.

\title{
1. Introdução
}

Reconhecer o trabalho de artistas populares e identificar a sua expressividade por meio de obras que resgatam a memória e a identidade cultural local, são elementos que compõem a linguagem significante e sensível do homem no decorrer da história.

No intuito de aproximar a comunidade estudantil a uma compreensão da memória e da identidade cultural local mediante a catalogação dos monumentos públicos produzidos pelas mãos de artistas populares locais, a proposta de criação de um inventário em formato digital e virtual para a organização e centralização dos dados foi sugerida pelos próprios estudantes de nosso grupo de pesquisa após a conclusão das etapas de registro de fontes textuais, imagéticas e videográficas realizadas junto aos escultores Odenes Bueno de Oliveira (mais conhecido por Denis Paraná) e Ladislau Charry Filho.

Dessa forma, tanto no escopo do projeto (valorização da cultura local) quanto no formato de organização do inventário artístico (mídia digital), é possível estabelecer uma aproximação entre o trabalho em questão e o pensamento do educador Paulo Freire que, ao contrário do que aponta a visão de transmissão de conhecimentos em cursos fixos e por modelos curriculares rígidos, defende a importância de se respeitar o repertório e conhecimento de mundo dos estudantes.

Em outras palavras, a pesquisa teve como ponto inicial a apresentação de novos saberes acadêmicos, partindo da identificação do contexto cultural dos estudantes e remodelou-se a partir de novos horizontes de expectativas educativas. 
Primeiramente, através do reconhecimento das representações visuais (por meio dos monumentos públicos) que narram a formação do povoado, vila, freguesia e finalmente a cidade de Jaguariaíva, e na sequência por considerar a experiência prévia e a familiaridade no uso das tecnologias digitais por parte dos estudantes, os suportes digitais passaram a fazer parte da organização dos dados da pesquisa.

Para tanto, a criação de um inventário virtual vem integrar parte dos resultados parciais de ações vinculadas ao projeto de pesquisa intitulado "Inventário das artes plásticas da cidade de Jaguariaíva" do Instituto Federal do Paraná, Campus Jaguariaíva, tendo a participação da comunidade acadêmica do curso técnico em Biotecnologia Integrado ao Ensino Médio.

Durante o exercício de 2017 e 2018, o projeto contou com a participação de dois estudantes voluntários e um discente bolsista do programa de fomento à iniciação científica, PIBICJr-CNPq (o fomento ao estudante compreendeu o período de março/17 a março/18).

O inventário virtual (em fase de desenvolvimento) nada mais é do que um website chamado "Inventário virtual dos monumentos e obras plásticas da cidade de Jaguariaíva/PR", criado pelo grupo de trabalho através da plataforma virtual Webnode (plataforma digital para construção de sites para uso pessoal, educacional ou empresarial).

Nesse sentido, além da otimização de recursos materiais, uma vez que, para a manipulação digital e virtual de informações o grupo necessita apenas de um equipamento tecnológico digital (seja um dispositivo móvel ou um computador) supõe-se que a escolha por este suporte digital seja capaz de viabilizar maior acesso ao diálogo entre objeto de pesquisa (monumentos catalogados que comunicam a relação entre identidade e memória, matéria e forma, criador e sua obra) junto à sociedade que está cada vez mais inserida nos espaços virtuais e na cibercultura.

\section{Jaguariaíva e sua identidade cultural a partir de algumas representações visuais}

Jaguariaíva é uma cidade paranaense com população de pouco mais de 34 mil habitantes (IBGE, 2017) e está localizada na região centro-oriental do estado. Com 195 anos de fundação, o município carrega traços da história do Brasil Colônia ao resgatar-se a época do ciclo econômico do tropeirismo que contribuiu para o desenvolvimento de muitos povoados da região dos Campos Gerais a partir do século XVII. Para os autores Antonio Carlos Frasson e Silvestre Alves Gomes (2010), o termo ‘tropeiro' foi concebido 
em razão das tropas, que eram constituídas principalmente de muares para serem comercializadas em Sorocaba-SP, onde se realizavam grandes feiras desses animais, o que promovia o comércio de outros produtos, causando grande movimentação nesse povoado que rapidamente prosperava. Além das mulas, a mercadoria mais valorizada na época, os tropeiros (proprietários e/ou condutores de tropas) transportavam também gêneros alimentícios, produtos manufaturados, inclusive os importados da Europa, e também faziam intercâmbio de informações (GOMES, FRASSON, 2010, p. 1).

Logo, visto que Jaguariaíva era também a rota de ligação dessas tropas entre as cidades de Viamão/RS e Sorocaba/SP, a sua formação da identidade cultural (alimentação, religião, música, dança, vestimentas, entre outros costumes) passa a receber expressiva contribuição da presença dos tropeiros, uma vez que, em cada local de pouso "fez-se surgir um novo tipo de relacionamento que veio reformular as relações sociais existentes. Foi a do sistema comercial configurando-se em um novo espaço para atender as necessidades dos tropeiros" (GOMES, FRASSON, 2010, p. 7).

A repercussão e a relevância econômica de tal movimento (tropeirismo) ocorrido no Brasil Colônia rendeu importantes registros pictográficos da região dos Campos Gerais pelas mãos do artista francês Jean-Baptiste Debret durante a Missão Artística Francesa.

De acordo a professora e pesquisadora Adalice Maria de Araújo (2006), o pintor poderia ser considerado como o maior cronista do Brasil do século XIX, uma vez que, segundo a autora, Debret foi o principal responsável por registrar e retratar de forma iconográfica e escrita aspectos da natureza e da organização social das pessoas que viviam nas diversas localidades do território brasileiro, reunindo seus trabalhos na obra "Viagem Pitoresca e Histórica ao Brasil”, que foi publicada primeiramente em Paris entre 1834 e 1839.

Segundo Araújo, a passagem do artista pelas cidades do Paraná teve duração de aproximadamente dois meses, período em que visitou as cidades de Jaguariaíva, Piraí do Sul, Castro, Ponta Grossa, Guarapuava, Palmeira, Lapa, Curitiba, Paranaguá e Guaratuba.

A composição em técnica de aquarela intitulada "Fazenda Jaguariaíva" (Figura 1), foi produzida por Debret em 1827, ressaltando-se os aspectos naturais do município, tais como as araucárias (árvores típicas dos Campos Gerais), as serras e os recursos hídricos consideravelmente abundantes na região. 


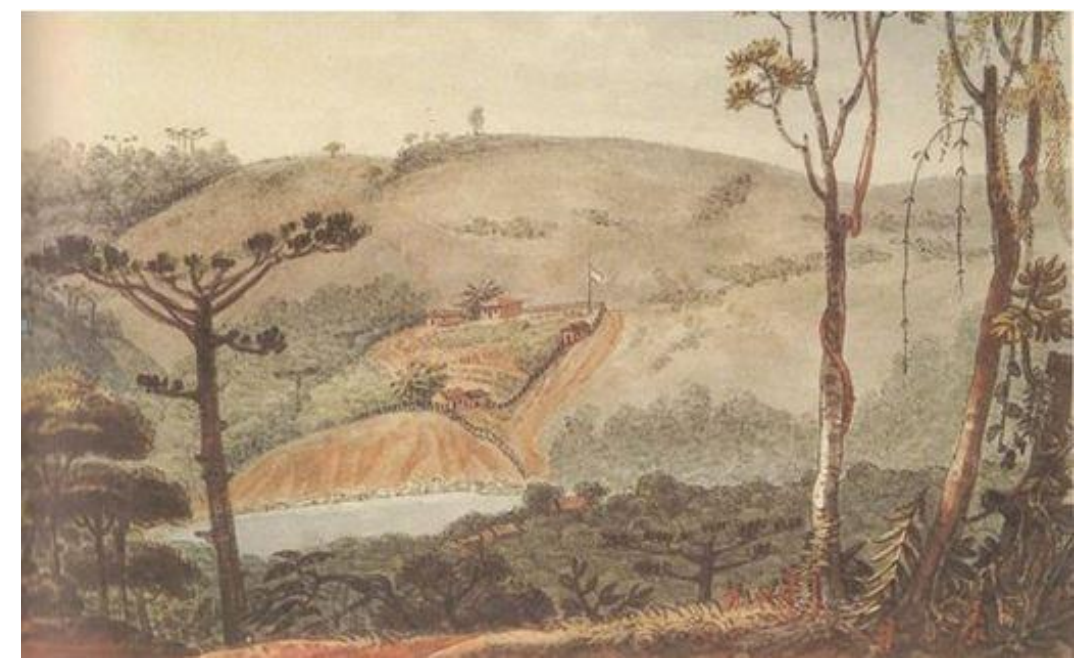

Figura 01 - Fazenda Jaguariaíva, de Jean Baptiste Debret. Aquarela. 1827. 15,7 x 22,5 cm Fonte: www.pinterest.com (2016)

Passados quase dois séculos desde a produção desta aquarela, embora a paisagem bucólica da cidade esteja dividida entre espaços urbanizados e áreas de plantio de florestas de eucalipto e de pinos que movimentam a indústria madeireira da região, ainda é possível nos conectarmos com o tempo pregresso através da linguagem visual presente nos monumentos públicos, seja pela escultura "O descanso do Tropeiro", que marca o local frequentado e utilizado como pouso pelos tropeiros durante o percurso das comitivas entre os estados do Rio Grande do Sul e São Paulo (Figura 2), seja pela representatividade da população que vive nas áreas rurais através da escultura "O Sertanejo" (Figura 3), ou ainda pela representação de um felino num dos principais acessos à cidade (Figura 4).

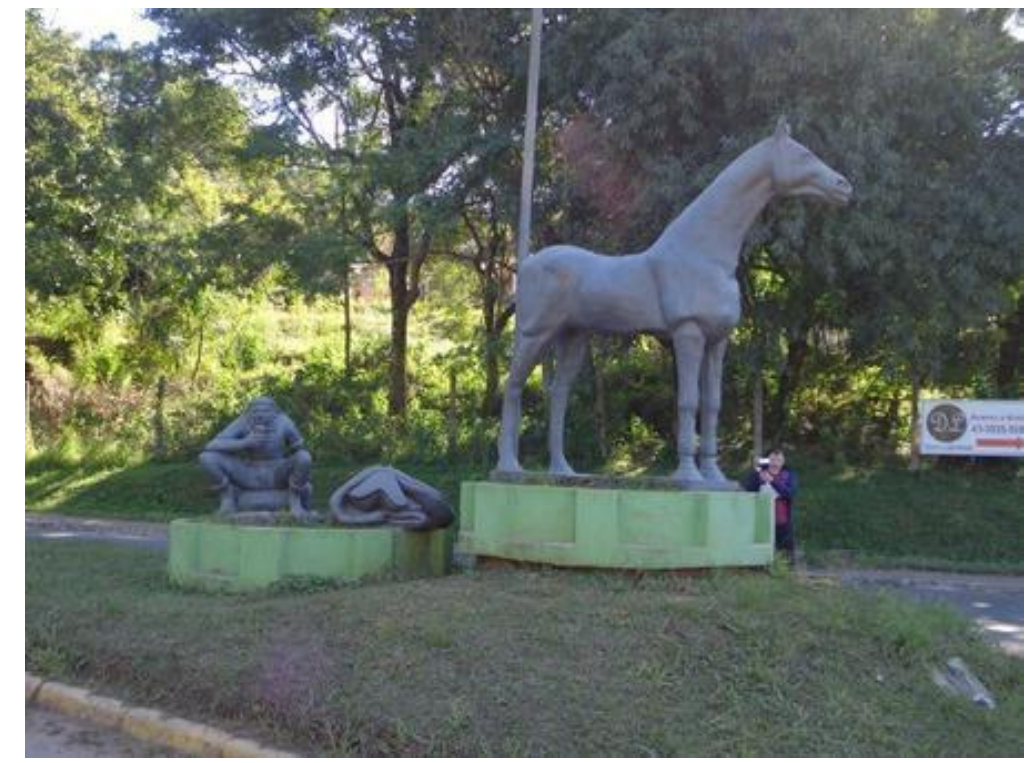

Figura 2 - Descanso do tropeiro. Escultura em concreto. Denis Paraná. 1998. Fonte: Os autores. 
Entende-se que tais referências imagéticas como os exemplos citados acima, podem colaborar para o processo de educação patrimonial e o devido reconhecimento de seu valor artístico- histórico-cultural junto à comunidade estudantil e comunidade em geral.

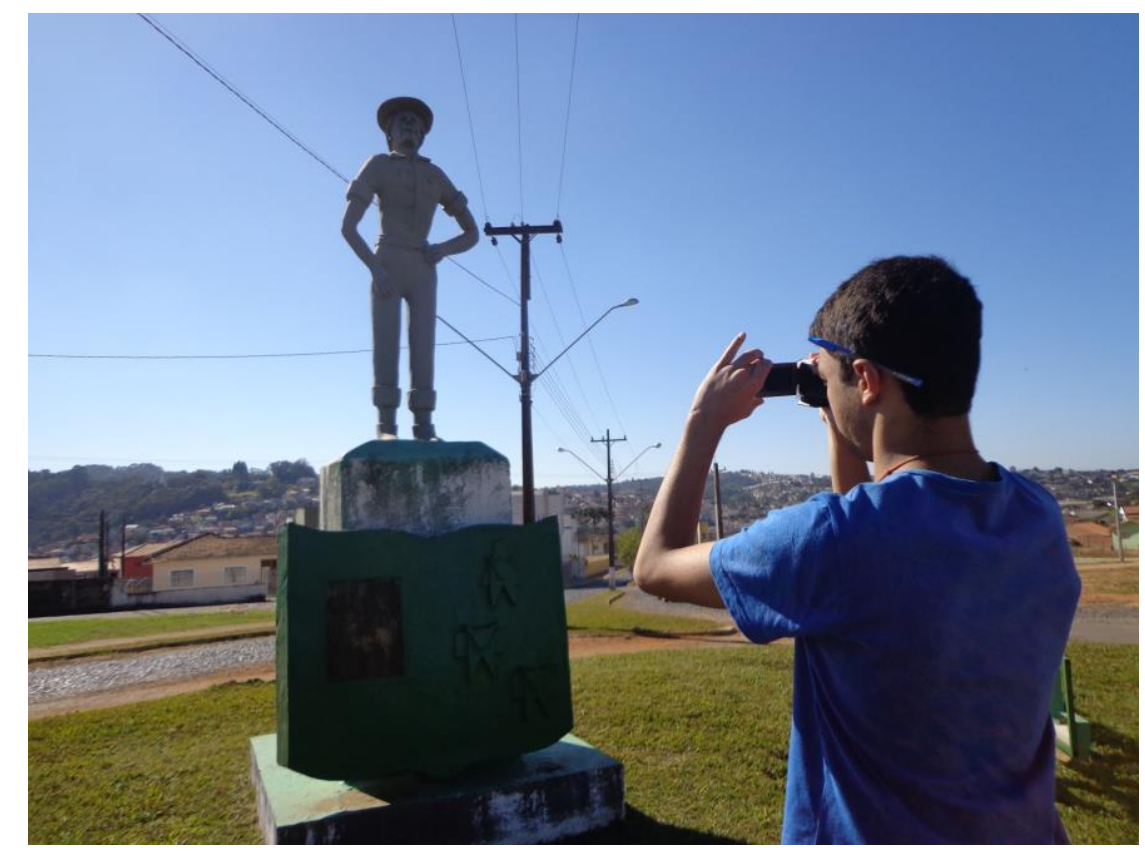

Figura 3 - O Sertanejo. Escultura em concreto. Denis Paraná. 1998. Fonte: Os autores

A motivação para a apresentação de tais referências imagéticas aos estudantes do IFPR do Campus Jaguariaíva surgiu após uma conversa em uma das aulas do componente curricular de Arte realizada no ano de 2016 quando constatou-se o desconhecimento ou desinteresse de grande parte dos estudantes quanto à importância em se estabelecer conexões entre identidade e memória, matéria e forma, e em compreender de que maneira se dá o processo criativo do criador e sua obra. 


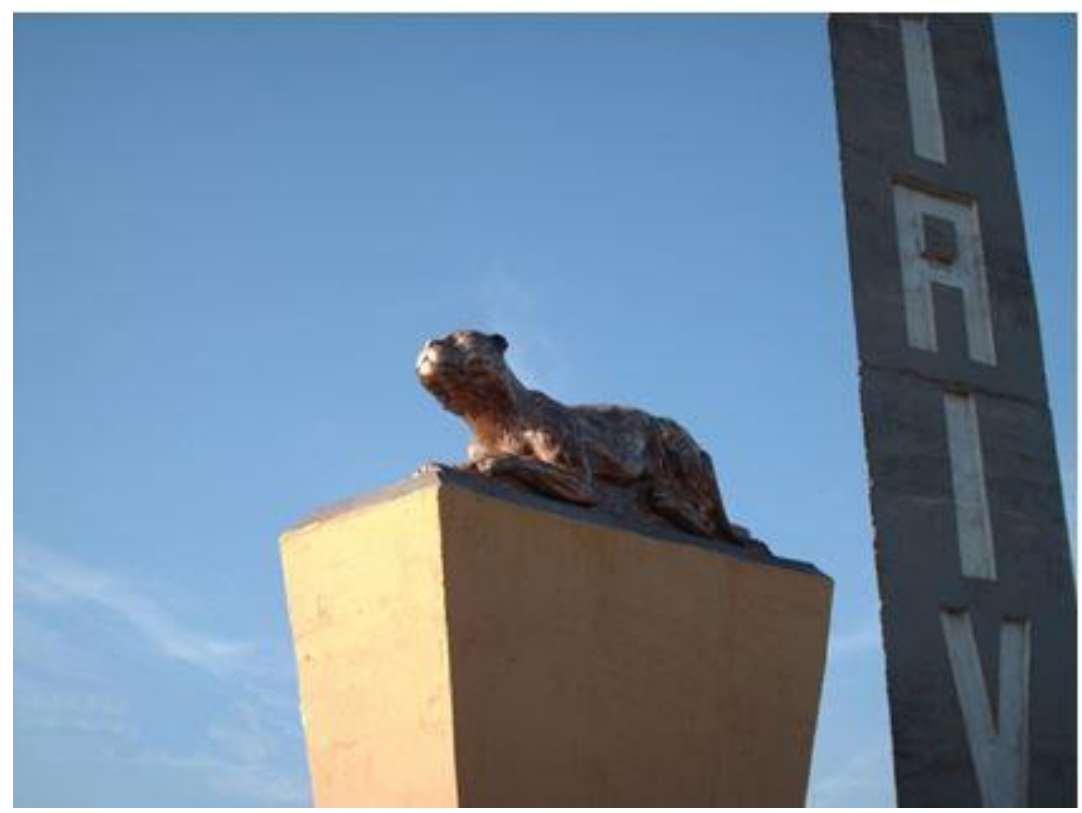

Figura 04 - Jaguar. Escultura em bronze. Ladislau Charry. Sem data. Fonte: Os autores.

Na concepção de Fayga Ostrower (1987), tais relações estão imbricadas na cultura de um povo ao envolver a forma em que os indivíduos de um grupo agem, levando em consideração as experiências coletivas transmitidas de forma material ou imaterial de uma geração para outra.

No que se refere ao processo de conscientização do indivíduo mediante a influência cultural, a autora pondera que

O modo de sentir e o de pensar os fenômenos, o próprio modo de sentir-se e pensarse, de vivenciar as aspirações, os possíveis êxitos, e eventuais insucessos, tudo se molda segundo ideias e hábitos particulares ao contexto social em que se desenvolve o indivíduo. Os valores culturais vigentes constituem o clima mental para o seu agir. Criam as referências, discriminam as propostas, pois, conquanto os objetivos possam ser de caráter estritamente pessoal, neles se elaboram possibilidades culturais. Representando a individualidade subjetiva de cada um, a consciência representa a sua cultura (OSTROWER, 1987, p. 16).

Atentando-se a tais preceitos e entendendo que as ações simbólicas materializadas pelo processo criativo do indivíduo representam a ordenação e a ampliação da sensibilidade de como o homem enxerga e influencia o mundo que o cerca, o projeto pautou-se também na legislação que visa o apoio, a valorização e a difusão das manifestações culturais brasileiras.

\section{O inventário como instrumento de preservação de bens culturais}


De acordo com a Constituição Federal de 1988, em seu artigo 216, parágrafo $1^{\circ}$,

O Poder Público, com a colaboração da comunidade, promoverá e protegerá o patrimônio cultural brasileiro, por meio de inventários, registros, vigilância, tombamento e desapropriação, e de outras formas de acautelamento e preservação (CF. 1988).

Para tanto, é por meio da menção do inventário como instrumento de promoção e de difusão dos bens culturais que as ações ampliam-se para um formato virtual, possibilitando a reunião de dados em uma única plataforma, compreendendo informações básicas dos monumentos inventariados, tais como: características físicas, estado de conservação, importância histórica e sua localização.

$\mathrm{Na}$ concepção do Instituto do Patrimônio Histórico e Artístico Nacional - IPHAN (2015), o termo "inventário" pode ser considerado peça-chave para a descrição detalhada de bens patrimoniais, além da proteção e preservação mediante a atualização dos dados sobre os bens culturais.

Para o andamento das etapas de pesquisa e de coleta de dados o grupo de pesquisa pautou-se nos referenciais e parâmetros gerais contidos no manual "Educação Patrimonial: Inventários Participativos", material este, sugerido pela coordenação geral de identificação e registro do IPHAN - Instituto do Patrimônio Histórico e Artístico Nacional, em contato realizado no ano de 2016.

\section{A obra e seu criador: Afinal, quem são os artistas populares Denis Paraná e Ladislau Charry Filho?}

Como resultado das entrevistas realizadas com os artistas populares locais, os estudantes puderam ampliar o conhecimento sobre as referências e técnicas distintas de criação de esculturas utilizadas pelos dois artistas em questão.

No segundo semestre de 2017 (conforme registro fotográfico da Figura 5), o escultor Odenis Bueno de Oliveira, mais conhecido como Denis Paraná, concedeu entrevista à equipe do projeto. Artista autodidata e descendente de índios, Denis nasceu no ano de 1956 no município de Jaguariaíva.

Embora tenha realizado dois trabalhos em cimento que são referência no contexto histórico da cidade (O Descanso do Tropeiro e O Sertanejo), o escultor salienta que sua principal fonte de inspiração surge da matéria bruta proveniente dos nós de pinho, raízes de 
árvores ou blocos de madeira e acrescenta que, de muitas obras já concretizadas com temáticas religiosas ou do cotidiano do povo do campo, foram as esculturas surreais que lhe renderam maior satisfação e realização pessoal no ato de criação. Para o artista, as obras surreais surpreendem ao tomar a forma desejada sem a realização de esboço prévio.

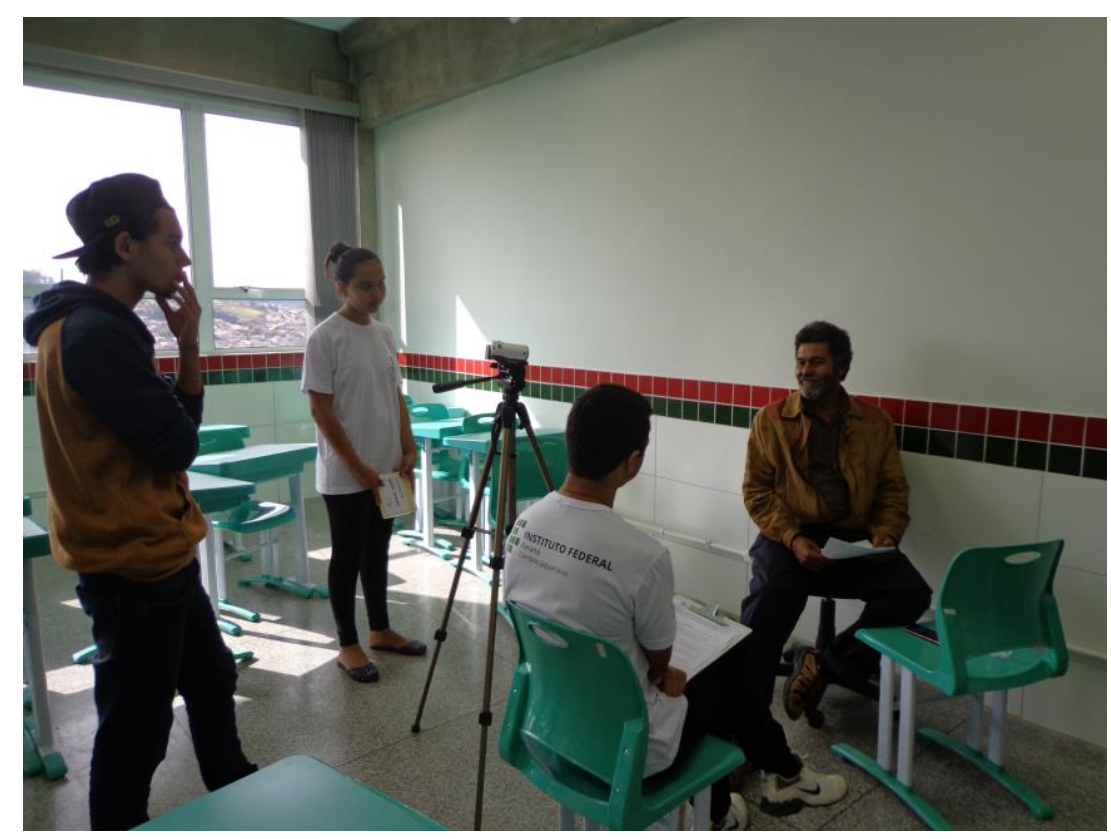

Figura 5- Entrevista com o escultor Denis Paraná. 2017. Fonte: Os autores.

Cabe destacar que a trajetória do artista é marcada com sua forte atuação em defesa da arte popular local e regional, tanto que em 2008, Denis foi um dos 12 artistas populares paranaenses mencionados no livro "Em nome do Autor", obra esta que, com o incentivo do Ministério da Cultura, reuniu o trabalho de 500 artistas plásticos do território brasileiro.

Além de fazer parte desta significativa coletânea de artistas brasileiros, Denis também expôs suas produções artísticas em inúmeros espaços culturais dos estados do Paraná e de São Paulo, principalmente entre o início da década de 90 até 2004, com destaque na Mostra Coletiva "Os Visionários", promovida pelo Museu de Arte Contemporânea de Curitiba em 1989 e a Mostra Individual "Do tosco ao tridimensional: a arte de Recicriar", realizada pelo SESC de Ponta Grossa no ano de 2004.

Em 1989 o artista foi premiado no Segundo Salão de Arte Religiosa da PUC/PR, além de ter colaborado para a fundação da Casa da Cultura Dr. João Batista da Cruz em Jaguariaíva.

Atualmente, Denis dedica-se na confecção de móveis de madeira sob encomenda para a obtenção de renda. 
O outro entrevistado foi o artista plástico Ladislau Chary Filho. O encontro aconteceu no primeiro semestre de 2018 (conforme Figura 6), na cidade de Carambeí, Paraná, local em que Chary reside atualmente em companhia de sua esposa e uma das filhas.

Nascido em 08 de janeiro de 1957, o escultor também é natural do município de Jaguariaíva e tem descendência húngara.

Artista autodidata, é o único na região a trabalhar com esculturas em bronze, resimármore e cobre, dando formas aos seus projetos artísticos tendo como temas preferidos os que se relacionam com o trabalho do homem do campo, como, por exemplo, o agricultor arando a terra e o tropeiro com o seu cavalo.

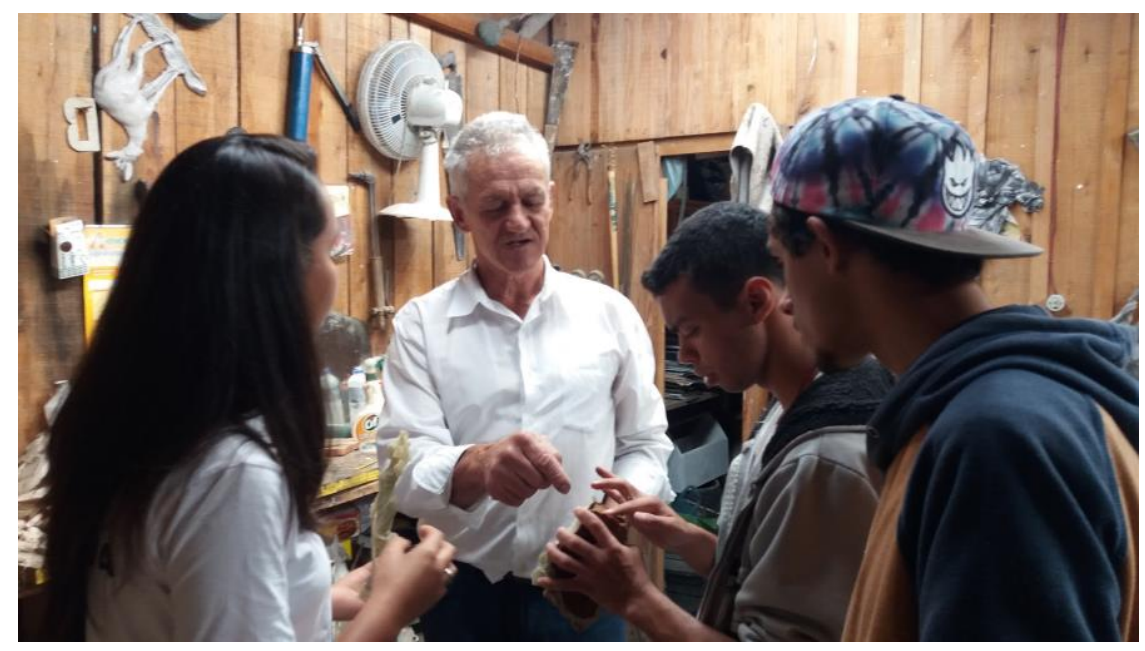

Figura 5- Ateliê do escultor Ladislau Chary Filho. 2018.

Fonte: Os autores.

Chary relata que o seu envolvimento com o ambiente artístico aconteceu quando ainda era criança, época em que aprendeu com o seu avô a técnica de recozimento do cobre. Mas foi na fase da adolescência que suas primeiras esculturas em baixo-relevo criadas a partir de rochas encontradas na região de Jaguariaíva-PR e Itararé-SP tomaram as devidas formas com profusão técnica e refinamento.

Como mencionado anteriormente, Chary foi o autor do jaguar esculpido em bronze, felino que faz parte de um dos símbolos do município de Jaguariaíva, monumento este, localizado numa das vias de acesso à cidade, convidando os visitantes a conhecerem um pouco mais da "Tyaguariahibá", que em origem tupi-guarani pode ser entendida como o "rio da onça brava".

E é pela capacidade que o artista plástico tem de transpor para a obra toda a sua sensibilidade e inventividade, que o escultor Ladislau reside hoje na cidade de Carambeí-PR, 
em virtude da demanda de trabalhos alusivos às comemorações do centenário da imigração holandesa que aconteceu em 2011.

\section{A utilização de tecnologias digitais para a criação de um inventário artístico virtual}

Visto que as convergências digitais estão cada vez mais presentes no cotidiano das pessoas, seja a partir da mobilidade possibilitada pela virtualização do tempo e espaço através do uso de dispositivos móveis ou de computadores portáteis, seja pelas inúmeras funcionalidades permitidas pela inteligência artificial e pela internet 4.0, a comunicação e as relações de interação e de interatividade entre os sujeitos refletem em todos os campos, e a educação também é parte deste contexto.

Na concepção dos pesquisadores e professores Adriana Vaz e Rossano Silva (2016), “a ideia de espaço virtual está cada vez mais presente nas nossas atividades diárias, pois os computadores, as redes digitais e a internet já fazem parte da nossa rotina" (VAZ e SILVA, 2016, p. 199).

Desta forma, optou-se pelas técnicas associadas ao processo de virtualização dos dados obtidos até o momento para a alimentação das informações do inventário virtual.

Espera-se que os pontos positivos deste suporte sejam a possibilidade de exploração textual não-linear das informações, a autonomia para que os indivíduos possam "caminhar" pelo ambiente virtual, de maneira que todos os conteúdos disponíveis possam ser acessados, independente do trajeto por eles elencado.

Nessa perspectiva Francimary Macêdo Martins afirma que

A leitura em ambiente hipertextual eletrônico significa uma promoção de leitura eficiente, quando cada leitor pode utilizar seu repertório particular de percepções e de conhecimentos para estabelecer a compreensão da informação, tornando o conhecimento um objeto coletivo de descoberta e de construção de seus constructos, de conhecimento de si mesmos e dos outros, formando um universo conectado de saberes. (MACÊDO, 2010, p. 06)

A partir dessa reflexão, o inventário artístico deste projeto deverá ser disponibilizado de forma digital e virtual a fim de expandir a capacidade de comunicação e de publicização da pesquisa, conferindo características de interação entre os agentes envolvidos. 


\section{Reflexões finais}

A plataforma virtual encontra-se em fase de formatação dos dados e ainda não está disponível e aberto ao público para acesso aos conteúdos.

No tocante à contribuição do projeto para a formação acadêmica dos estudantes envolvidos, é possível observar que no decorrer das atividades desenvolvidas os mesmos passaram a apresentar maior entendimento acerca das relações estabelecidas entre a identidade cultural, história e do local onde vivem.

Outro fator positivo deste projeto foi poder proporcionar aos educandos uma vivência prática na exploração e utilização dos recursos tecnológicos digitais em formatos de vídeos, textos, sons, imagens e de ambientes virtuais.

Desta forma, espera-se que, ao final das ações propostas pelo projeto, a página virtual seja divulgada para amplo acesso pela comunidade acadêmica na expectativa de promover a reflexão e a valorização das obras artísticas que compõem a identidade cultural de Jaguariaíva.

\section{Referências}

ARAÚJO. A. M. Dicionário das Artes Plásticas no Paraná. Volume I. Acervo de informações Artes na Web, 2015. Disponível em: http://www.artesnaweb.com.br/index.php?pagina=home\&abrir=arte\&acervo=1062. Acesso em: 20 nov. 2016. (Home page)

BRASIL (1988). Constituição da República Federativa do Brasil. Brasília, Senado Federal, 1988. Disponível em: http://www.planalto.gov.br/ccivil_03/Constituicao/ Emendas/Emc/emc91.htm. Acesso em: 15 set. 2017. (Documentos oficiais)

BRASIL. IBGE. Instituto Brasileiro de Geografia e Estatística. Censo 2017. Brasil, Paraná, Jaguariaíva. Disponível em: https://cidades.ibge.gov.br/brasil/pr/jaguariaiva/panorama. Acesso em: 23 dez. 2018. (Documentos oficiais)

BRASIL. Instituto do Patrimônio Histórico e Artístico Nacional. Departamento de Patrimônio Material. Educação Patrimonial: inventários participativos: manual de aplicação. Brasília, IPHAN, $2016 . \quad$ Disponível em: http://portal.iphan.gov.br/uploads/publicacao/inventariodopatrimonio_15x21web.pdf. Acesso em: 23 out. 2016. (Documentos oficiais)

FRASSON, A. C.; GOMES, S. A. Tropeirismo: Processo civilizatório da região sul do Brasil. Portal da Secretaria da Educação do Estado do Paraná, 2010. Disponível em: http://www.educadores.diaadia.pr.gov.br/arquivos/File/2010/artigos teses/2010/Historia/artig os/frasson_artigo.pdf. Acesso em: 23 dez. 2018. (Artigo em Periódico Digital) 
MARTINS, F. M. ESTADO DA ARTE SOBRE LEITURA HIPERTEXTUAL em ambiente virtual de aprendizagem. Revista digital Hipertextus. Edição n.4, Jan/2010. Disponível em: http://www.hipertextus.net/ volume4/Francimary-Macedo-MARTINS.pdf. Acesso em: 28 ago. 2017. (Artigo em Periódico Digital)

OSTROWER, F. Criatividade e Processos de Criação. Petrópolis: Editora Vozes, 1987. 192 p. (Obra completa)

VAZ, A.; SILVA, R. Fundamentos da linguagem visual. Curitiba: Editora InterSaberes, 2016. 320 p. (Obra completa) 